\title{
Pengaruh Level Suhu Mesin Tetas Terhadap Daya Tetas dan Bobot Tetas Puyuh Padjadjaran
}

\author{
Jefrianus Neonnub ${ }^{1, a}$, Lovita Adriani ${ }^{2}$, Iwan Setiawan ${ }^{2}$ \\ ${ }^{1}$ Mahasiswa Program Studi Pascasarjana Fakultas Peternakan Universitas Padjadjaran \\ ${ }^{2}$ Program Studi Fakultas Peternakan Universitas Padjadjaran \\ Jln. Raya Bandung - Sumedang Km 21 Jatinangor, Sumedang 45363. \\ aemail: jefrineonnub@gmail.com
}

\begin{abstract}
Abstrak
Tujuan penelitian ini untuk mengetahui pengaruh level suhu mesin tetas terhadap daya tetas dan bobot tetas day old quail (DOQ) puyuh Padjadjaran. Penelitian secara eksperimental, menggunakan Rancangan Acak Lengkap (RAL), 3 level suhu diulang sebanyak 7 kali. Level suhu mesin tetas pada fase hatcher dan setter terdiri atas $\mathrm{T} 1=37,0, \mathrm{~T} 2=37,5$, dan $\mathrm{T} 3=38,0{ }^{\circ} \mathrm{C}$. Parameter yang diamati adalah daya tetas telur dan bobot tetas DOQ. Data penelitian diolah menggunakan analisis sidik ragam dan apabila memberikan hasil yang signifikan, dilanjutkan dengan Uji Duncan. Hasil penelitian memperlihatkan level suhu mesin tetas $37,5^{\circ} \mathrm{C}$ selama masa inkubasi menghasilkan daya dan bobot tetas DOQ puyuh Padjadjaran yang optimal.

Kata kunci: telur puyuh Padjadjaran, suhu mesin tetas, daya tetas, bobot tetas
\end{abstract}

\section{The Impact of Temperature Level Hatching Machine on Hatchability and Hatching Weight of Padjadjaran Quail}

\begin{abstract}
The aim of this study was to find out the impact of temperature level hatching machine on eggs hatchability and hatching weight of Padjadjaran quail. This study was conducted by Completely Randomized Design method (CRD), 3 levels of temperature which was repeated 7 times. Temperature of hatching machine on hatcher and setter were $T 1=37,0, T 2=37,5$, and $T 3=38,0{ }^{\circ} \mathrm{C}$. Parameters observed were eggs hatchability and hatching weight. The research data was processed using variance analysis and if it gave significant results, followed by Duncan Test. The result showed that temperature level of hatching machine $37.5^{\circ} \mathrm{C}$ during incubation period provides the egg hatchability and hatching weight of Padjadjaran quail optimally.
\end{abstract}

Keywords: Padjadjaran quail, hatching machine temperature, Hatchability, Hatching Weight

\section{Pendahuluan}

Salah satu sumberdaya genetik ternak yang dikembangkan di Pusat Pembibitan Universitas Padjadjaran, Kecamatan Jatinangor, Kabupaten Sumedang Jawa Barat adalah puyuh Padjadjaran. Puyuh Padjadjaran selain yang berasal dari Coturnix coturnix japonica murni terseleksi ada juga yang merupakan hasil persilangan antara galur coklat dan galur hitam. Hasil silangan tersebut ditujukan untuk mendapatkan bibit puyuh berkualitas dengan bibit unggul yang memproduksi telur dengan bobot telur yang cukup besar dan produksi telur yang tinggi.

Ketersediaan bibit puyuh yang berkualitas di pasaran masih terbatas, sehingga puyuh Padjadjaran dapat menjadi salah satu alternatif untuk mengisi kekosongan bibit tersebut. Memproduksi bibit puyuh yang berkualitas selain memerlukan pola breeding yang tepat, juga diperlukan kinerja penetasan yang baik. Salah satu teknologi yang dapat mendukung perkembangan populasi puyuh adalah mesin 
tetas. Mesin tetas pada prinsipnya mengikuti pola eram alami mengikuti sifat-sifat alamiah induk yang mengerami telur, yaitu membalik telur yang dierami, menyesuaikan suhu dan kelembaban yang sesuai untuk perkembangan embrio (Subiharta dan Yuwana, 2012). Pengaturan suhu dan kelembaban yang tepat pada periode inkubasi sesuai dengan kebutuhan perkembangan embrio dapat menghasilkan hasil tetasan dengan produktivitas dan pertumbuhan yang baik.

Suhu inkubasi atau suhu spesifik embrio merupakan faktor paling penting yang akan mempengaruhi hasil tetasan serta kualitas day old quail (DOQ). Faktor - faktor yang berpengaruh terhadap temperatur embrio adalah produksi panas embrio, suhu udara di dalam inkubator periode setter dan hatcher, kelembaban udara serta kecepatan aliran udara. Telur akan menyerap panas dari udara sekitarnya selama periode pertama inkubasi, mengingat suhu embrio sedikit lebih rendah dari suhu inkubator. Selanjutnya embrio akan kehilangan panas selama paruh kedua inkubasi akibat produksi panas karena metabolisme meningkat (French, 1997). Kondisi selama inkubasi sangat mempengaruhi pematangan saluran percernaan, pemanfaatan kuning telur, pengembangan otot, jantung, metabolisme tiroid, dan termoregulasi serta tingkat pertumbuhan setelah menetas (Wineland, dkk., (2006); Christensen, dkk., (2004); Christensen, dkk., (2006); Decuypere (1994) dalam Shim dan Pesti, 2011).

Suhu inkubasi adalah faktor yang paling penting untuk perkembangan embrio dan daya tetas. Suhu yang ideal biasanya memungkinkan mencapai daya tetas dan bobot tetas maksimum. Dua hal penting dalam penetasan yang perlu diperhatikan dan dapat mempengaruhi perkembangan embrio yaitu suhu dan $\mathrm{O}_{2}$ (Meijerhof, 2009). Sampai saat ini suhu inkubasi telur unggas liar masih bervariasi dari $33^{\circ} \mathrm{C}$ sampai $39^{\circ} \mathrm{C}$, sedangkan kisaran $37^{\circ} \mathrm{C}$ sampai $38^{\circ} \mathrm{C}$ merupakan suhu optimal inkubasi untuk ternak unggas lokal (Visschedijk, 1991). Suhu inkubasi telur puyuh masih bervariasi dari $37,5^{\circ} \mathrm{C}$ hingga $40^{\circ} \mathrm{C}$ (Elena Popescu, Miclosanu, 2007). Pengaturan suhu mesin tetas untuk penetasan telur puyuh adalah $37^{\circ} \mathrm{C}$ dan $38^{\circ} \mathrm{C}$. Secara umum, suhu inkubasi yang tinggi $\left(38^{\circ} \mathrm{C}, 39^{\circ} \mathrm{C}, 40^{\circ} \mathrm{C}\right.$, dan $41^{\circ} \mathrm{C}$ ) akan mengakibatkan berat tetas menurun, sedangkan pada suhu inkubasi yang lebih rendah $\left(34^{\circ} \mathrm{C}, \quad 35^{\circ} \mathrm{C}, \quad 36^{\circ} \mathrm{C}, \quad\right.$ dan $\left.\quad 37^{\circ} \mathrm{C}\right)$ akan menghasilkan daya tetas dan bobot tetas yang rendah (Romao, dkk., 2009). Popescu-Micloşanu Elena (2007) menjelaskan bahwa kelembaban selama inkubasi untuk burung puyuh dengan kisaran $55-70 \%$ dalam mesin tetas. Mengingat sangat pentingnya kondisi suhu mesin tetas, sementara suhu yang tepat pada masa inkubasi masih bervariasi, maka penelitian level suhu mesin tetas terhadap daya dan bobot tetas telur puyuh Padjadjaran perlu dilakukan.

\section{Materi dan Metode}

Telur tetas yang digunakan untuk penelitian berasal dari parent stock puyuh Padjadjaran yang dikembangkan di Pusat Pembibitan Puyuh Fakultas Peternakan Universitas Padjadjaran. Parent stock yang dipelihara untuk menghasilkan telur tetas memiliki umur yang seragam yaitu 12 minggu dengan sex rasio jantan:betina 1:3. Secara keseluruhan, telur tetas yang digunakan berjumlah 1.050 butir, yang diinkubasikan ke dalam 21 buah mesin tetas otomatis.

Telur tetas yang terkumpul diseleksi yang berukuran sedang, bentuknya ovoid, tekstur halus, dan tidak retak (utuh). Telur yang telah diseleksi sebanyak 1.050 butir selanjutnya dimasukkan ke dalam 21 buah mesin tetas semi otomatis sehingga setiap mesin tetas diisi sebanyak 50 butir. Mesin tetas dan telur tetas difumigasi menggunakan kalium permanganat $\left(\mathrm{KmnO}_{4}\right)$ dan formalin $40 \%$ dengan imbangan 1:2. Proses pemutaran telur selama masa inkubasi dilakukan secara manual sebanyak 4 kali dalam sehari. Kelembaban mesin tetas diatur sebesar $60 \%$ pada fase setter dan $70 \%$ pada fase hatcher. Pengontrolan suhu inkubator agar sesuai level suhu perlakuan dilakukan secara rutin 3 kali dalam sehari pada pukul 06.00 WIB, $12.00 \mathrm{WIB}$, dan 18.00 WIB.

Penelitian eksperimental dengan bentuk Rancangan Acak Lengkap (RAL), 3 level suhu mesin tetas $(\mathrm{T} 1=37,0, \mathrm{~T} 2=37,5$, dan $\mathrm{T} 3=$ $38,0^{\circ} \mathrm{C}$ ), masing-masing diulang 7 kali sehingga terdapat 21 unit percobaan dan setiap ulangan diisi telur sebanyak 50 butir. Parameter yang diamati adalah daya tetas dan bobot tetas. Data hasil penelitian daya tetas telur dan bobot tetas DOQ diolah menggunakan analisis sidik ragam dan apabila hasil yang signifikan, dilanjutkan uji 
Duncan's Multiple Range Test (DMRT) dengan bantuan software SPSS 17.

Parameter Penelitian yaitu daya tetas dan bobot tetas. Daya tetas dapat diketahui dengan menghitung jumlah telur yang telah berhasil menetas dari jumlah telur fertil. Bobot tetas diukur dengan menimbang anak puyuh yang baru menetas setelah $95 \%$ bulunya mengering.

\section{Hasil dan Pembahasan}

\section{A. Daya Tetas}

Rataan daya tetas telur puyuh Padjadjaran hasil penelitian disajikan secara lengkap pada Tabel 1 .

Tabel 1 menunjukan perlakuan suhu mesin tetas menghasilkan daya tetas telur yang signifikan $(\mathrm{P}<0,05)$. Suhu mesin tetas $37,5^{\circ} \mathrm{C}$ (T2) menghasilkan persentase daya tetas telur paling tinggi (84\%), sedangkan daya tetas paling rendah $(67 \%)$ dihasilkan pada suhu mesin tetas $37,0{ }^{\circ} \mathrm{C}$ (T1). Apabila mengacu kepada Direktorat Pembibitan Ternak (2011) yang menetapkan standar mutu atau persyaratan daya tetas telur puyuh sebesar $70 \%$, maka daya tetas telur puyuh Padjadjaran hasil penetasan pada suhu inkubasi $37,5{ }^{\circ} \mathrm{C}$ (T2) dan $38,0{ }^{\circ} \mathrm{C}$ (T3) tergolong baik.

Tingginya persentase daya tetas telur pada suhu inkubasi $37,5^{\circ} \mathrm{C}$ (T2) diduga karena suhu tersebut merupakan kondisi optimal yang dapat mendukung pertumbuhan embrio secara baik sehingga mampu menetas dengan sempurna. Keadaan inkubasi yang optimal mampu menghasilkan daya tumbuh dan berkembangnya organ secara proporsional. Periode inkubasi dengan suhu terlalu rendah atau dibawah suhu optimal saat penetasan mengakibatkan embrio sensitif pada pertumbuhan dan perkembangannya sehingga kesulitan menetas (Ono et. al., 1994). Kondisi tersebut dapat mengakibatkan daya tetas yang rendah. Suhu yang terlalu tinggi mengakibatkan dehidrasi atau kekeringan pada telur (Nakage, dkk., 2003), sehingga dapat mengakibatkan pertumbuhan embrio yang tidak sempurna.

Daya tetas kurang optimal yang dihasilkan pada suhu inkubasi $37,0{ }^{\circ} \mathrm{C}$ (T1) dan $38,0{ }^{\circ} \mathrm{C}$ (T3) erat kaitannya dengan penyusutan bobot telur akibat pengaturan suhu. Semakin tinggi suhu maka semakin besar susut telur sehingga mengalami pengeluaran panas yang lebih besar melalui evaporasi dan sangat besar kemungkinan embrio gagal menetas akibat dehidrasi karena penguapan besar, sebaliknya semakin rendah suhu maka susut tetas semakin kecil memungkinkan embrio tidak bermetabolisme dan menyebabkan embrio gagal menetas. Penyusutan telur terjadi karena penguapan gas-gas dan cairan yang berada dalam telur menyebabkan bobot telur menurun. Cairan dalam telur berfungsi melarutkan zat zat nutrisi untuk pertumbuhan embrio. Penyusutan bobot telur diakibatkan oleh pengaruh suhu dan kelembaban selama periode inkubasi akan menghambat perkembangan embrio yang berdampak pada daya tetas (Tullet dan Burton (1982).

Table 1. Rataan Daya Tetas Telur Puyuh Padjadjaran Hasil Penelitian

\begin{tabular}{cc}
\hline Perlakuan & Rataan \\
Level Suhu Mesin Tetas & Daya Tetas (\%) \\
\hline T1 & $67,00 \pm 3,00^{\mathrm{c}}$ \\
T2 & $84,00 \pm 3,644^{\mathrm{a}}$ \\
T3 & $74,00 \pm 2,984^{\mathrm{b}}$ \\
\hline
\end{tabular}

Keterangan: T1: 37,0 , T2: 37,5 , dan $\mathrm{T} 3: 38,0{ }^{\circ} \mathrm{C}$; Superkrip huruf kecil yang berbeda pada kolom menunjukkan signifikasi $(\mathrm{P}<0,05)$. 
Table 2. Rataan bobot tetas puyuh padjadjaran hasil penelitian

Perlakuan

Level Suhu Mesin Tetas
Rataan

Bobot Tetas (g)

\begin{tabular}{cc}
\hline T1 & $7,02 \pm 3,381^{\mathrm{b}}$ \\
T2 & $7,36 \pm 2,807^{\mathrm{a}}$ \\
T3 & $6,97 \pm 3,174^{\mathrm{b}}$ \\
\hline
\end{tabular}

Keterangan: T1: 37,0 , T2: 37,5 dan $\mathrm{T} 3: 38,0{ }^{\circ} \mathrm{C}$; Superskrip huruf kecil menunjukkan signifikasi

$$
(\mathrm{P}<0,05) \text {. }
$$

B. Bobot Tetas

Rataan bobot tetas puyuh Padjadjaran hasil penelitian disajikan pada Tabel 2.

Tabel 2 menunjukan level suhu mesin tetas $37,5{ }^{\circ} \mathrm{C}$ (T2) menghasilkan bobot tetas lebih tinggi (7,36\%) dibandingkan dengan level suhu mesin tetas $37,0{ }^{\circ} \mathrm{C}$ (T1) dan $38,0{ }^{\circ} \mathrm{C}$ (T3). Sedangkan bobot tetas antara perlakuan $\mathrm{T} 1$ dan T3 tidak menunjukkan perbedaan yang signifikan $(\mathrm{P}>0,05)$. Secara umum bobot tetas puyuh Padjadjaran pada penelitian ini cukup baik dan lebih tinggi dibandingkan dengan bobot tetas Coturnix-Coturnix Japonica, yaitu sebesar 6,35 g (Adeyanu dkk., (2014)

Tingginya bobot tetas DOQ puyuh Padjadjaran yang dihasilkan oleh mesin tetas dengan level suhu inkubasi $37,5^{\circ} \mathrm{C}$ menunjukkan bahwa pada level suhu tersebut embrio dapat tumbuh secara optimal karena suhu lingkungan mesin tetas yang ideal. Panas ideal yang diterima oleh telur melalui kerabang mengakibatkan perkembangan dan pertumbuhan embrio terjadi secara baik. Hal ini sesuai dengan pendapat Elvira, dkk. (1994) bahwa suhu sangat berpengaruh terhadap bobot telur dan perkembangan embrio di dalam telur serta mempengaruhi bobot tetas. Suhu yang tinggi selama masa inkubasi akan mengakibatkan tingginya penguapan gas dan air pada telur (Nakage, 2003). Kondisi ini dapat mengakibatkan penyusutan bobot telur yang pada akhirnya berdampak pada bobot tetas yang lebih rendah. Peningkatan ion $\mathrm{Ca}^{+}$dan $\mathrm{Na}^{+}$dari cairan allantoic akibat transfer dalam membran chorioallantoic (CAM) yang aktif mengakibatkan kehilangan air selama periode berlangsungnya penetasan, hal ini memaksa sistem osmoregulatory embrio memberi respon dengan bertambahnya jumlah air yang hilang, sehingga mengakibatkan bobot tetas menurun (Davis, dkk., 1988).

Bobot tetas yang rendah dan tidak berbeda nyata antar perlakuan T1 dan T3 menunjukkan bahwa kondisi level suhu yang lebih rendah dan lebih tinggi dari $37,5^{\circ} \mathrm{C}$ pada masa inkubasi telah mengakibatkan pertumbuhan embrio tidak sempurna. Hal ini sesuai dengan pendapat Simkiss (1980) bahwa pertumbuhan embrio pada suhu inkubasi rendah menjadi lambat, sedangkan pada suhu inkubasi tinggi mengakibatkan pertumbuhan embrio lebih cepat tetapi berdampak pada bobot tetas yang rendah.

\section{Kesimpulan}

Level suhu mesin tetas $37,5^{\circ} \mathrm{C}$ selama masa inkubasi memberikan daya tetas telur dan bobot DOQ puyuh Padjadjaran yang optimal.

\section{Ucapan Terimakasih}

Ucapan terimakasih penulis sampaikan kepada Bapak Sarif sebagai tenaga teknisi di Breeding Centre Puyuh Fakultas Peternakan Universitas Padjadjaran yang telah membantu dalam penyediaan telur puyuh, dan Bapak Iwan Hadiana, S.Pt., selaku tenaga PLP yang telah membantu dalam pelaksanaan penetasan.

\section{Daftar Pustaka}

Adeyanu, T.M., S.S. Abiola, J.A. Adegbite, and S.A. Adeyanju. 2014. Effect of egg size on hatchability of Japanese quail (Coturnix-Coturnix Japonica). (JETEAS) 5 (7): 133-135.

Christensen, M., Heilmann-Clausen, J., Walleyn, R., Adamcik, S. 2004. Woodinhabiting fungi as indicators of nature 
value in European beech forests. EFI proceedings.

Davis, T. A., S. Shen, and P. A. Ackerman. $\quad 1988 . \quad$ Embryonic Osmoregulation: Consequences of High and Low Water Loss During Incubation of The Chicken Egg. Journal of Experimental Zoology. (245): (144-156).

Direktorat Perbibitan Ternak. 2011. Pedoman Pembibitan Burung Puyuh yang Baik (Good Breeding Practice). Deptan. Jakarta. Indonesia.

Decuypere, E., C. Vega, T. Bartha, J. Buyse, J. Zoons, andG.A.A. Albers, 1994. Increased sensitivity to triiodothyro-nine (T3) of broiler lines with a high susceptibility forascites. Br. Poult. Sci. 35:287-297.

Elena Popescu. Miclosanu, (2007). "Cresterea pasarilor pentru productia de oua”, Ed. Printech, Bucuresti.

Elvira S., Soewarno T. Soelcarto dan SS. Mansjoer. 1994. Studi Komparatif Sifat Mutu dan Fungsional Telur Puyuh dan Telur Ayam Ras. Hasil Penelitian Bul. T dan Indwb.1 Pm, Vd. V no.3. Tir. 1994

French, N. A. 1997. Modeling incubation temperature: the effects of incubator design, embryonic development, and egg size. Poult Sci. 76 (1):124-133.

Meijerhof, R. 2009. The influence of incubation on chick quality and broiler performance. Pages 167-170 in 20th Annual Australian Poultry Science Symposium. Sydney. Australia.
Nakage E., Cardozo J. P., Pereira GT, Queiroz S. A dan Boleli I. C., 2003. Effect of Temperature on Incubation Period, Embryonic Mortality, Hatch Rate, Egg Water Loss And Partridge Chick Weight (Rhynchotus Rufescens). Rev. Bras. Cienc. Avic. (5); (2); (131-135).

Ono H, Hou PCL, Tazawa H. Tanggapan pengembangan embrio ayam terhadap perubahan akut pada suhu lingkungan: Studi noninvasif tingkat hart. Israel Journal of Zoology 1994, 40: 467-480.

Romao, J. M., T. G. V. Moraes. and R. S. C. Teixeira. 2009. Effect of relative humidity on incubation of Japanese quail eggs. Livestock Research for Rural Development, .21, (3).

Simkiss K. 1980. Eggshell porosity and the water metabolism of the chick embryo. Journal of Zoology; 192:1-8.

Shim M.Y. dan Pesti G.M., 2011. Effects of incubation temperature on the bone development of broilers. Poultry Science (9); (10); (1867-1877).

Tullet, S.G. dan F.G. Burton. 1982. Factor affecting the weight and water status of chick and hatcsh. British Poult. Sci. 2.(32): 361-369.

Visschedijk, A. H. J. 1991. Physic and Physiology of Incubation. British Poultry Science. 23: 3-20.

Subiharta dan Yuwana, D. M., 2012. Pengaruh Penggunaan Bahan Tempat Air dan Letak Telur di Dalam Mesin Tetas yang Berpemanas Listrik pada Penetasan Itik Tegal. Seminar Nasional Kedaulatan Pangan dan Energi 1-7. 